\title{
Developing multivariable probabilistic flood loss models for companies
}

\author{
Lukas Schoppa ${ }^{1,2, a}$, Heidi Kreibich ${ }^{1}$, Tobias Sieg ${ }^{1,2}$, Kristin Vogel $^{2}$ and Gert Zöller ${ }^{2}$ \\ ${ }^{1}$ Helmholtz Centre Potsdam German Research Centre for Geosciences - GFZ, Telegrafenberg, 14473 Potsdam, Germany \\ 2 University of Potsdam, Am Neuen Palais 10, 14469 Potsdam, Germany
}

\begin{abstract}
Decision-making in flood risk management strongly relies on the accurate estimation of monetary flood loss. Recent advancements in the field promote the use of multivariable flood loss models that consider a multitude of damage controlling factors beyond inundation depth. However, the development of novel flood loss models excluded companies for the most part, albeit their considerable contribution to total flood damages. In this methodological study, we propose three probabilistic approaches to flood loss modelling for companies that intrinsically quantify prediction uncertainty. We fit a random forest, a Bayesian network and a Bayesian regression to company loss data for buildings $(\mathrm{n}=545)$, which stem from four post-event surveys after floods in Germany. Posterior predictive checks, which give insight on the plausibility of the proposed models, prove that all candidate models reproduce essential characteristics of the observed loss data properly. The predictive training errors suggest that the random forest and the Bayesian network outperform the Bayesian regression. We trace the difference in predictive training error back to distinct model structures and emphasize that the presented model checks represent the groundwork for a detailed model validation.
\end{abstract}

\section{Introduction}

Flood loss modelling is an integral component of flood risk assessment (Merz et al., 2004, 2010a; Olesen et al., 2017). In the appraisal of direct monetary flood loss, stagedamage functions represent the current standard (Merz et al., 2010b; Meyer et al., 2013). Stage-damage functions relate the flood intensity, mostly expressed through the water depth at the flooded building, to the damage grade of an asset. Since stage-damage functions solely depend on water depth, they can be classified as univariable flood loss models. The majority of such models (e.g. Huizinga et al., 2017; International Commission for the Protection of the Rhine (ICPR), 2016; Penning-Rowsell et al., 2005; Scawthorn et al., 2006) feature a set of stage-damage functions for different types of assets (e.g. building, content, equipment), occupancy (e.g. residential, infrastructure, industrial), and further discriminators (e.g. construction material, number of stories).

However, flood loss is determined by a large number of additional factors beyond water depth (Merz et al., 2010b; Middelmann-Fernandes, 2010; Thieken et al., 2005). This gave rise to mutlivariable flood loss models, which take into account multiple predictors at the same time (Meyer et al., 2013). Many proposed multivariable flood loss models originate from the field of machine learning or statistics and comprise decision trees (e.g. Carisi et al., 2018; Hasanzadeh Nafari et al., 2016a; Merz et al., 2013), multivariable generalized regression (e.g. Van Ootegem et al., 2015; Zhai et al., 2005), or Bayesian models (e.g. Lüdtke et al., 2019; Sairam et al., 2019;

a Corresponding author: lukas.schoppa@gfz-potsdam.de

DOI 10.3311/FLOODRisk2020.11.12
Wagenaar et al., 2018). Despite considerable uncertainties in flood loss estimation, the vast majority of existing flood loss models is deterministic (Gerl et al., 2016). Hence, state-of-the-art flood loss modeling fails to account for predictive uncertainty (Merz et al., 2004; Meyer et al., 2013). Only few novel flood loss models quantify the uncertainty in their loss estimates (Rözer et al., 2019; Schröter et al., 2014; Sieg et al., 2019; Vogel et al., 2014)

These recent advancements in flood loss estimation predominantly regarded the residential sector, although companies exhibit similar loss potential during severe flood events (e.g. German Federal Ministry of the Interior, 2013; Mechler \& Weichselgartner, 2003; Thieken et al., 2016). However, there exist a handful of multivariable flood loss models for companies. For instance, rule-based (Kreibich et al., 2010; Seifert et al., 2010), synthetic (Hasanzadeh Nafari et al., 2016b), or tree-based models (Sieg et al., 2017; Sultana et al., 2018). Other promising approaches from the field of Bayesian statistics such as Bayesian networks (Vogel et al., 2012, 2014, 2018; Wagenaar et al., 2018) or Bayesian regression (Rözer et al., 2019; Sairam et al., 2019), only exist for the residential sector.

In this methodological study, we develop, check, and compare three innovative flood loss models for building loss to companies, namely, Bayesian networks, Bayesian regression, and random forest. We learn the models on basis of surveyed loss data from major flood events in Germany. The proposed models are mutlivariable and probabilistic. That is, they infer flood loss from multiple predictors and provide probability statements along with 
their loss predictions. After model derivation we conduct sanity checks with the fitted models in order to assess whether the models are well specified and capable of reproducing actual observations. Further we provide a first estimate of the predictive model performance by computing training errors for deterministic and probabilistic loss forecasts. Thorough model checking represents a key element in the development of novel flood loss models, especially in the context of complex statistical modeling techniques (Gabry et al., 2019; Gelman et al., 2013).

\section{Survey data}

We develop the proposed models based on empirical survey data of company flood loss to buildings, which were collected in the aftermath of severe flood events in Germany. The dataset is composed of four individual surveys conducted between 2002 and 2013 and contains information on flood intensity, company characteristics, emergency and precautionary measures, flood experience, and flood loss of affected companies (Kreibich et al., 2007; Thieken et al., 2016). The surveyed floods occurred in the catchments of the Danube, Elbe, Oder, and Rhine. For a detailed description of the collection methodology for the loss data we refer to Kreibich et al. (2007).

In accordance to findings from the literature and existing multivariable flood loss models, we compose a set of predictors from the collected survey answers for modeling. Table 1 features the eight predictor variables and the response variable, relative loss. The first group of predictors describes the flood severity. Water depth and inundation duration at the affected company premises were queried in the surveys and proved to be decisive factors for company flood loss (Kreibich et al., 2010; Sieg et al., 2017). Further, we conducted an extreme value analysis at discharge gauges along affected river stretches in order to compute regionalized return periods for the surveyed flood events. We calculated the return periods following Elmer et al. (2010). The next group of variables concerns company characteristics and is composed by the economic sector of the company, the spatial circumstances of the affected company premises, and the size of the company in terms of the number of employees (Kreibich et al., 2010; Sieg et al., 2017). The final group of predictors is composed of flood experience and precaution. Similar to previous studies (Kreibich et al., 2010; Schröter et al., 2014; Wagenaar et al., 2018), we express the flood experience of a company through the number floods which affected the same company site before the surveyed event. Finally, we compute company precaution from eight survey questions on the implementation of distinct emergency and precautionary measures similar to Sieg et al., (2017). The resulting precaution variable is a ratio on the interval $[0,1]$, where well prepared companies receive high values and vice versa. Table 2 lists the individual precautionary measures from which the ratio is calculated. We compute the precaution ratio as follows:

$$
\text { pre }=\frac{n I}{n P}
$$

where $n I$ is the number of precautionary measures which were implemented prior to the occurrence of the surveyed flood and $n P$ is the number of measures which could have been implemented potentially.

\begin{tabular}{|c|c|}
\hline Variable & Scale $^{\mathrm{a}}$, unit, range \\
\hline \multicolumn{2}{|l|}{ Predictors } \\
\hline $\begin{array}{l}\text { Water depth } \\
\text { wd }\end{array}$ & c: $0-825 \mathrm{~cm}$ above ground \\
\hline $\begin{array}{l}\text { Inundation duration } \\
d u r\end{array}$ & c: $0-720 \mathrm{~h}$ \\
\hline $\begin{array}{l}\text { Return period } \\
r p\end{array}$ & c: $1-909$ a \\
\hline $\begin{array}{l}\text { Size } \\
\text { size }\end{array}$ & c: 1-650 employees [-] \\
\hline $\begin{array}{l}\text { Business sector } \\
\text { sec }\end{array}$ & $\begin{array}{l}\text { n: (1) manufacturing, } \\
\text { (2) commercial, } \\
\text { (3) financial, } \\
\text { (4) service }\end{array}$ \\
\hline $\begin{array}{l}\text { Spatial situation } \\
\text { spat }\end{array}$ & $\begin{array}{l}\text { n: (1) more than one building, } \\
\text { (2) one entire building, } \\
\text { (3) one or more floors in shared } \\
\text { building, } \\
\text { (4) less than one floor in shared } \\
\text { building }\end{array}$ \\
\hline $\begin{array}{l}\text { Flood experience } \\
\exp \end{array}$ & $\begin{array}{l}\text { o: zero previous floods to five } \\
\text { or more previous floods ( } 6 \\
\text { classes) }\end{array}$ \\
\hline $\begin{array}{l}\text { Precaution ratio } \\
\text { pre }\end{array}$ & c: $0-1[-]$ \\
\hline \multicolumn{2}{|l|}{ Response } \\
\hline $\begin{array}{l}\text { Relative loss building } \\
\text { rloss }\end{array}$ & c: 0-1 [-] \\
\hline
\end{tabular}

${ }^{a}$ c: continuous, $n:$ nominal, o: ordinal

Table 1: Predictor $(n=8)$ and response $(n=1)$ model variables with their abbreviations. The second column states the scaling, unit, and observed range of each model variable.

The response variable, flood loss to buildings, is a ratio as well and expresses the monetary damage relative to the replacement cost of the building. This is beneficial for several reasons; for instance, it allows for the spatial and temporal transferability of the developed loss models (Merz et al., 2010b). The resulting relative loss is defined on the interval $[0,1]$, where a value of zero means no flood loss and a value of one represent a total loss of the building.

Figure 1 displays the model data, which contain 545 individual companies. The response variable, relative loss, is strongly skewed and a substantial share of the companies incurred either no $(32 \%)$ or a total $(4 \%)$ building loss. 

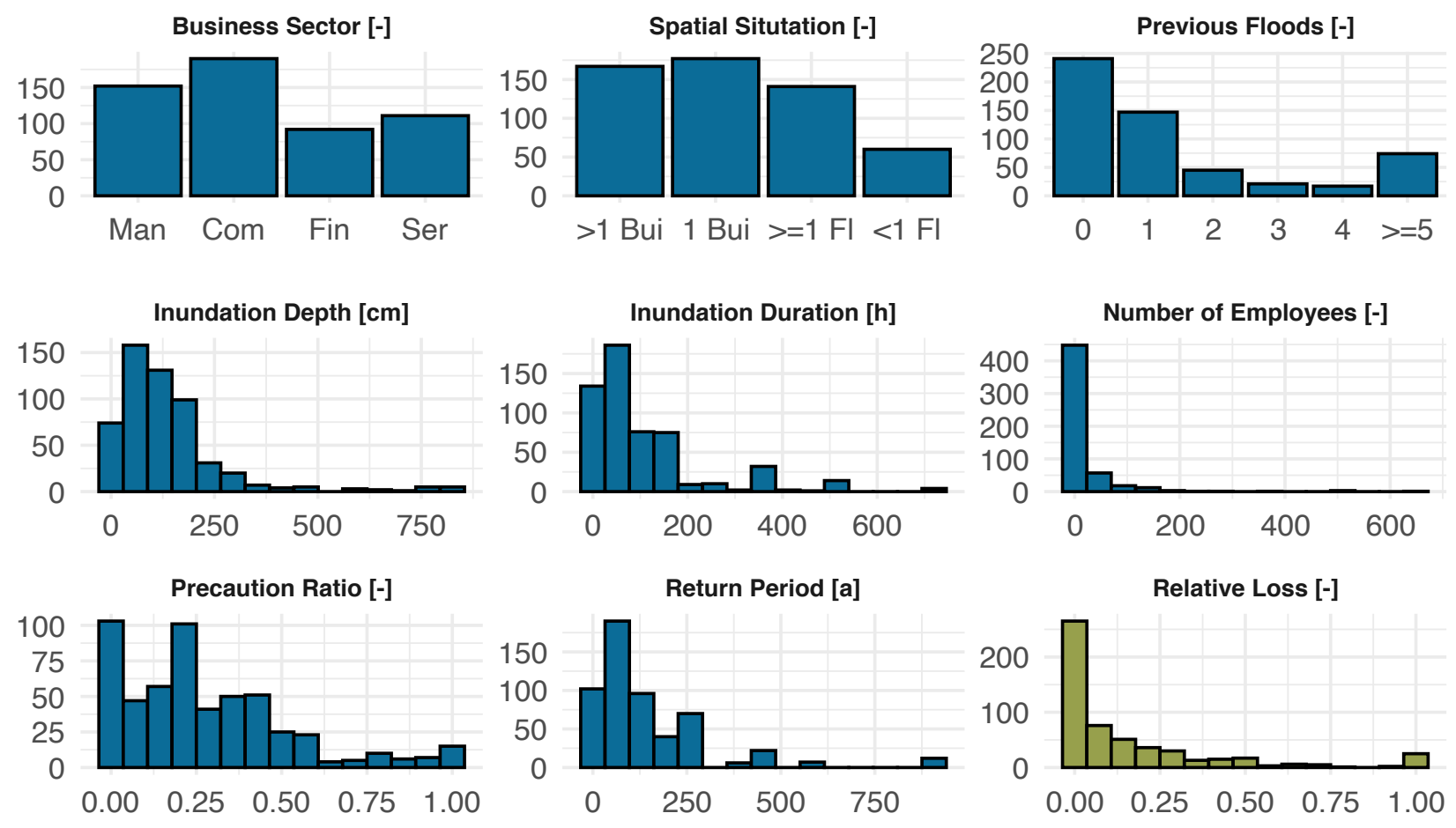

Figure 1: Survey data for company flood loss to buildings. Predictor variables ( $n=8$, blue) are characterized by different scaling and pronounced skewness, while the response variables relative loss (green) exhibits a bimodal distribution.

\section{Flood loss models}

\subsection{Random forests}

Random forest (RF) is an ensemble method from the field of machine learning (Breiman, 2001). A RF is composed of a large number of decision trees which are commonly unbiased but underlie strong variance (Hastie et al., 2009). The RF algorithm averages a large number of decorrelated trees which counteracts the variance of single trees but preserves their predictive accuracy. The decorrelation is achieved by two measures (James et al., 2013). First, trees are grown on distinct bootstrap samples of the training data and averaged during prediction yielding one ensemble forecast (bootstrap aggregation). Second, the construction of each tree is randomized in order to increase the difference across the ensemble members (random feature selection). The resulting RF routine provides forecasts with low bias and variance, and is particularly suited for modelling non-linear processes. Further, RFs are straightforward to implement as they accept continuous and discrete variables at the same time (Hastie et al., 2009).

We adapted the conventional RF routine (see e.g. Liaw \& Wiener, 2002) to advancements in tree-based learning and to the requirements of this study. On the one hand, we use the conditional inference algorithm for tree construction, since conventional regression trees are biased towards continuous variables (Hothorn et al., 2006). On the other hand, we employ the approach of Meinshausen (2006), which allows for predicting a conditional predictive distribution of the response variable instead of only a mean value. In this way, the proposed RF model provides probabilistic forecasts of relative loss just as the other two candidate models. This RF setup has been used in flood loss modelling before by Sieg et al. (2017, 2019). Two parameters control the RF routine, the number of trees in the ensemble $n_{\text {tree }}$ and the number of randomly selected predictors during tree construction $m_{t r y}$. Based on recommendations from the literature (Hastie et al., 2009; Liaw \& Wiener, 2002), we opt for $n_{\text {tree }}=1000$ and $m_{\text {try }}=3$.

\subsection{Bayesian networks}

A Bayesian network $(\mathrm{BN})$ is a probabilistic graphical model which encodes the statistical dependency among a set of random variables in a directed acyclic graph (Nagarajan et al., 2013). In a BN, variables are represented by nodes and probabilistic dependencies are indicated by connecting arcs between nodes. In its entirety, a BN visualizes the joint probability distribution between the variables in the graph. Due to restrictions in the possible distributions of continuous variables, the majority of BNs is discrete with the multinomial distribution being the underlying joint probability function. This joint probability function can be factorized in a set of local probability functions, one for each variable (Scutari, 2010):

$$
P\left(X_{1}, \ldots, X_{n}\right)=\prod_{i=1}^{n} P\left(X_{i} \mid \Pi_{X_{i}}\right)
$$

where $X_{i}$ are all $n$ variables of the $\mathrm{BN}$, and $\Pi_{X_{i}}$ are the respective parent nodes of $X_{i}$ in the directed acyclic graph, i.e., nodes that point to $X_{i}$. The local multinomial distributions of the $\mathrm{BN}$ are stored in conditional 
probability tables which represent the parameters of the model (Nagarajan et al., 2013; Scutari \& Denis, 2014).

We follow a common two-step procedure (Scutari, 2010) to establish the proposed BN flood loss model. First, we learn the graph structure of the network from the survey data by means of a structure learning algorithm. Afterwards, we estimate the values of the conditional probability tables conditional on the learned graph structure. Before learning the $\mathrm{BN}$, we discretized continuous variables to avoid assumptions on the families of distributions and to gain closed-form expressions (Vogel et al., 2014). We discretized the presumably most influential predictors water depth and precaution ratio (Kreibich et al., 2010; Sieg et al., 2017), and the response variable relative loss with ten bins. The remaining continuous variables were binned into five intervals, in order to balance model detail and complexity. In contrast to the other candidate models who return continuous estimations of relative loss, the predictions of the $\mathrm{BN}$ are discrete. In the interest of model comparability, we resampled the binned loss forecasts of the BN back to the real line on the interval $[0,1]$ according to the predicted probability weight of each relative loss bin. For each prediction we simulated 1000 samples of relative loss. Figure 2 shows the BN graph structure which we learned on the basis of the survey data.

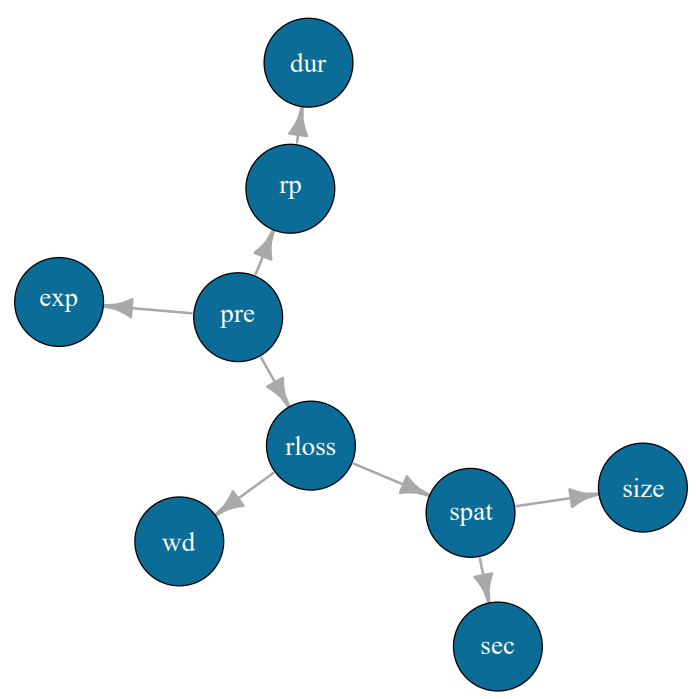

Figure 2: Bayesian network for building loss. We learned the graph structure from the survey data. Note that information is exchanged in both directions of an arc, independent of its orientation.

\subsection{Bayesian regression}

Implementing a Bayesian regression model (BR) requires an assumption about the distributional form of the response variable. For proportions, such as relative loss, the beta distribution is a common choice, since it covers the interval $[0,1]$ (Ferrari \& Cribari-Neto, 2004). However, the conventional beta distribution is not defined at extreme values of zero and one which are abundant in the survey data at hand. Hence, we follow the proposal of Ospina \& Ferrari (2010), who suggested a zero-and-one-inflated beta distribution. This mixture model explicitly accounts for an excess in zeros and ones through a Bernoulli distribution and reads as follows:

$$
\left\{\begin{aligned}
& \operatorname{beinf}(y \mid \lambda, \gamma, \mu, \phi)= \\
& \lambda(1-\gamma), \text { if } y=0 \\
& \lambda \gamma, \text { if } y=1 \\
&(1-\lambda) \operatorname{beta}(y ; \mu, \phi), \text { if } y \in(0,1)
\end{aligned}\right.
$$

where $y$ is the response relative loss, $\lambda$ is the zero-andone-inflation probability (i.e., the probability that the response is zero or one), and $\gamma$ is the conditional oneinflation probability (i.e., the probability that the response is one rather than zero). For interpretability, the beta distribution is reparametrized with $\mu$ and $\phi$ as mean and precision parameter (Ferrari \& Cribari-Neto, 2004).

The proposed BR is a distributional regression model, where all four parameters of the zero-and-one-inflated beta distribution are estimated through distinct regression terms. While we use all predictors to estimate the beta mean parameter $\mu$, the inflation parameters $\lambda$ and $\gamma$ are predicted by the most influential variables with respect to building loss, i.e. water depth, precaution, and spatial situation. Ultimately, we estimate the beta precision $\phi$ from water depth and precaution. By reducing the number of predictors for the inflation and precision parameters we reduce the total number of regression parameters which have to be estimated and, in turn, facilitate model convergence. The selection of the most influential parameters is based on the findings of Sieg et al. (2017) who found that the spatial situation exhibits particular explanatory power besides water depth and precaution. Continuous predictors were transformed in analogy to Yeo (2000), centered, and scaled to treat the skewness in the data.

Bayesian models derive posterior parameter distributions by using observed data to update prior parameter distributions, which reflect the initial plausibility of parameter values (McElreath, 2018). Priors should be chosen in a way, that they rule out unrealistic parameter values and at the same time allocate most probability mass on values leading to plausible model response (Gelman et al., 2017; Simpson et al., 2017). We followed this recommendation and assigned priors that suit our understanding of flood damage processes. For instance, the regression coefficient of the variable water depth received the prior $\operatorname{Normal}(1,1.5)$ with more probability mass on positive values, since we expect that larger inundation depths lead to higher flood loss.

It is often impossible to compute analytical solutions of the posterior. Therefore, we approximate the posterior distribution via Markov chain Monte Carlo (MCMC) sampling (see e.g. Gelman et al., 2013; McElreath, 2018). We configured the MCMC sampler to return 1000 samples from the posterior predictive distribution of relative building loss in order to match the number of samples from the other candidate models. A review of the MCMC 
Bayesian Network

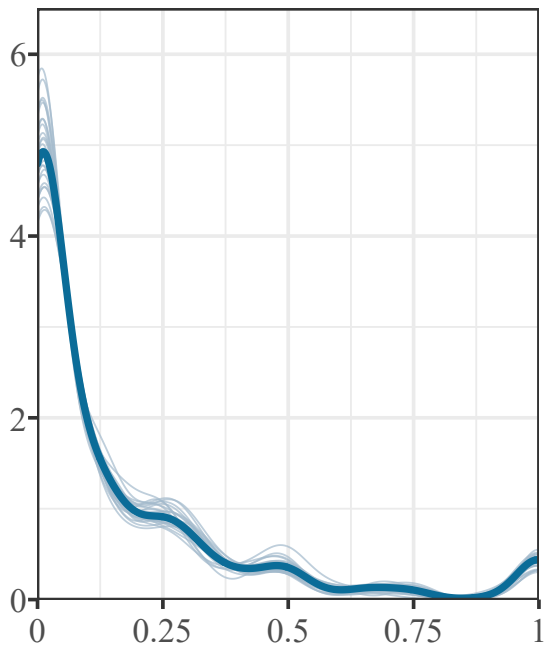

Bayesian Regression

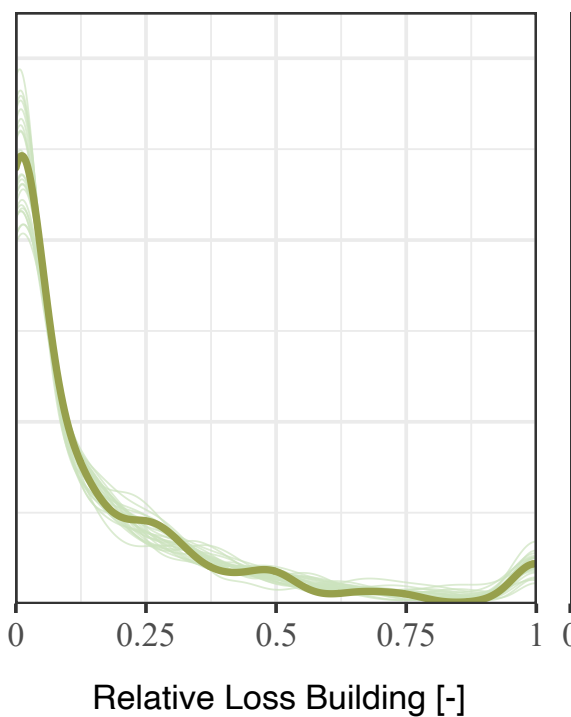

Random Forest

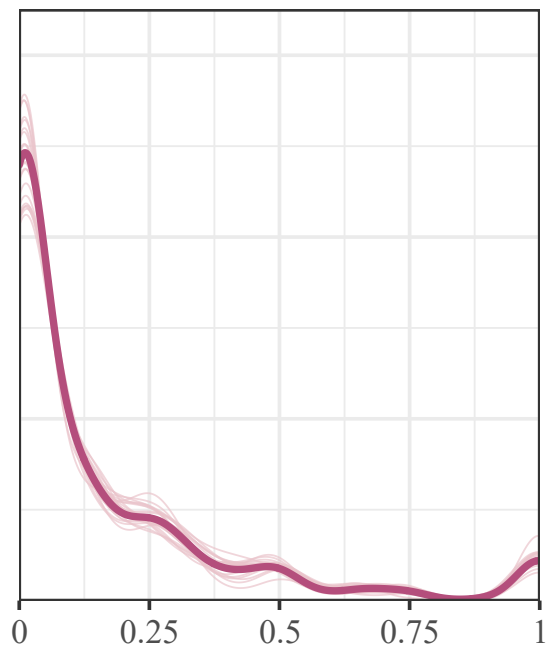

Figure 3: Overlay of relative loss distributions as observed in the data (single dark line) and simulated from the models (multiple bright lines). Each panel displays the overlay plot for one model (colour-coded) and features 25 simulated predictive distributions.

diagnostics and experiments with larger sample numbers showed that 1000 samples are sufficient to reliably estimate the posterior distribution of the model.

\section{Model comparison}

We assess the eligibility of the proposed flood loss models through posterior predictive checks. The idea of posterior predictive checks is popular in Bayesian inference and states that a well specified model should be capable of generating data that resembles the actually observed data (Gabry et al., 2019). In detail, we compare replications of relative loss from the models to the observed distribution of relative loss. If a model fits, the distributions of simulated and observed relative loss should match. For BN and BR, we obtain the replications of relative loss $y_{\text {rep }}$ from the posterior predictive distribution

$$
p\left(y_{\text {rep }} \mid y\right)=\int p\left(y_{\text {rep }} \mid \theta\right) p(\theta \mid y) d \theta
$$

where $y$ are the observations of relative loss and $\theta$ are the model parameters (Gelman et al., 2013). In case of the $\mathrm{RF}$, we evaluate the predicted conditional distribution of relative loss. Comparing characteristic features of observed and simulated data reveals whether the model is calibrated and, hence, able to reproduce essential characteristics of the data generating process or not. For flood loss models, it is particularly crucial to investigate model performance with regard to the amount of simulated total and no loss cases, since the loss distribution has direct impact on subsequent risk analysis. For instance, frequent low losses affect the average annual flood risk, and infrequent severe losses can increase the absolute loss of an event substantially. Note that posterior predictive checks use the same data for model fitting and checking (Gabry et al., 2019).
Furthermore, we compare the training errors of the candidate models to each other by means of three performance metrics. Again, the models are evaluated on the same data which were used for fitting the models. Although the training error overestimates the true model skill for unseen data (James et al., 2013), it is suited for a first estimate of the relative performance of the candidate models. We compare the proposed models on the basis of the following performance metrics:

1) The mean average error (MAE) for the mean of the predictive distribution

2) The mean bias error (MBE) for the mean of the predictive distribution

3) The continuous ranked probability score (CRPS) which evaluates the calibration and sharpness of the entire predictive distribution (e.g. Gneiting \& Katzfuss, 2014). The CRPS evaluates the complete probability distribution, but can be understood as an analogy to MAE for point estimates, since both measures are expressed in the unit of the response variable.

\section{Results}

Figure 3 shows an overlay of 25 simulated predictive distributions (multiple bright lines) from the three candidate models (color-coded) and the observed distribution (single dark line) of relative loss. The strong agreement between the simulated and the observed loss distributions across candidate models suggests that all models are able to reproduce the response variable. The simulated densities of RF resemble the observed loss distribution very closely and even reproduce the bulges in the relative loss data. The same applies to the simulations of $\mathrm{BN}$, which disperse slightly more around the observations. The posterior predictive distributions of BR deviate most strongly from the data and appear smoother than the simulations from the other models. For all models, 

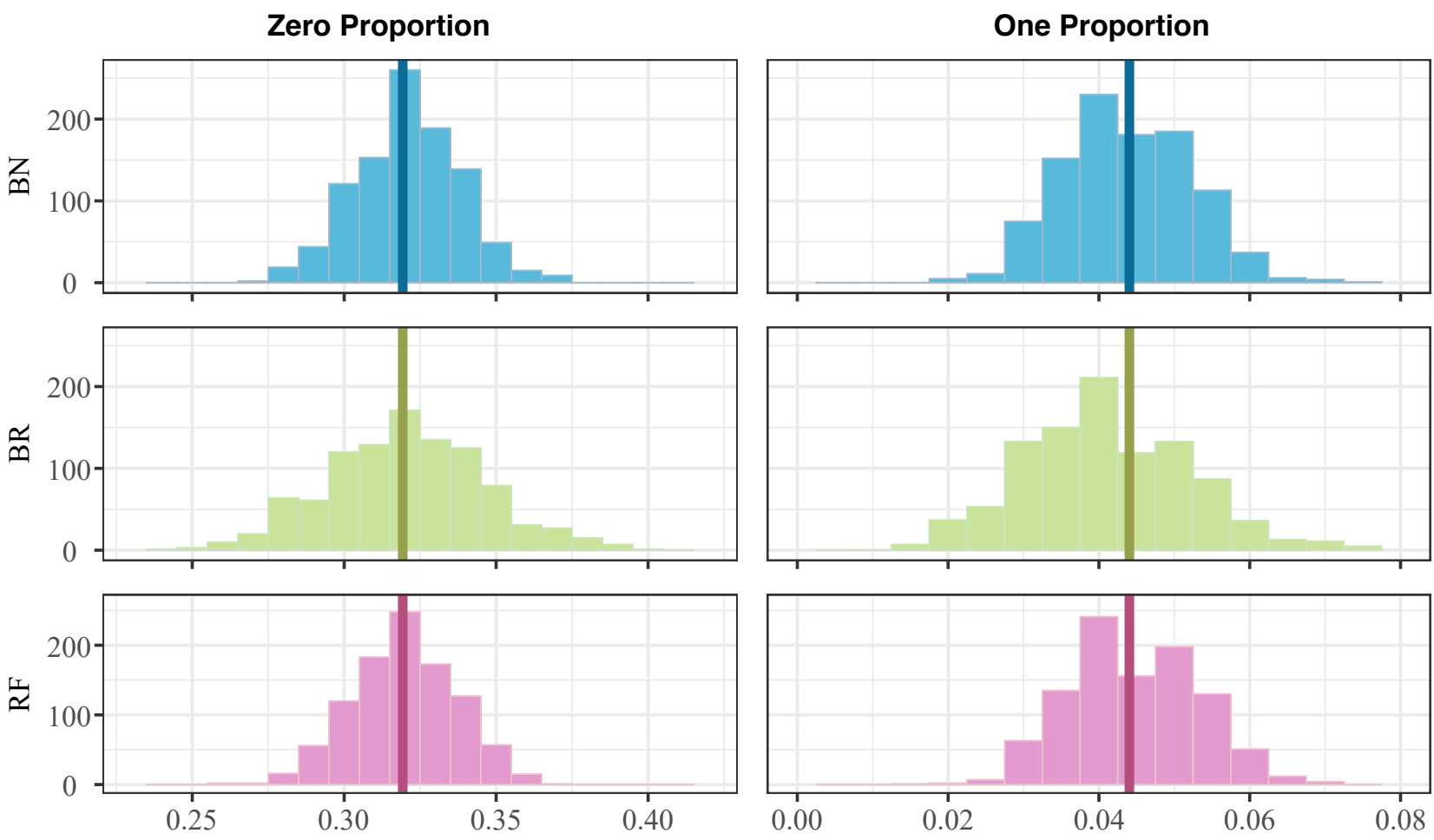

Figure 4: Observed and simulated proportions of zeros and ones in the variable relative loss for Bayesian networks (BN), Bayesian regression (BR), and random forest (RF). Each histogram (colour coded) summarizes the proportions of 1000 simulated datasets.

we observe the largest spreads in the simulations of loss at extreme magnitudes, i.e. values of zero and one. This variation is particularly pronounced for very low flood loss.

Figure 4 compares the proportions of zeros and ones in the simulated data to the shares in the survey data. The histograms summarize the proportions in the simulations, while the vertical lines indicate the observed ratio of zeros and ones. The plot reveals that all models reproduce the true proportion of zeros in the survey data well. The same applies to the simulated shares of ones. Yet, BR and RF tend to underestimate the number of total loss cases slightly. The variation in the simulations are more pronounced for $\mathrm{BR}$ in comparison to the remaining models. We find that all candidate models account for the considerable amount of no and total loss cases in the data sufficiently.

\begin{tabular}{|c|c|c|c|}
\hline Model & MAE & MBE & Mean CRPS \\
\hline BN & 0.1430 & -0.0003 & 0.0914 \\
\hline BR & 0.1566 & -0.0078 & 0.1007 \\
\hline RF & 0.1287 & -0.0009 & 0.0781 \\
\hline
\end{tabular}

Table 2: Mean average error (MAE), mean bias error, and mean continuous ranked probability score (CRPS) for Bayesian network (BN), Bayesian regression (BR), and random forest (RF). The listed performance measures show the training error of the models.

Table 2 summarizes the training performance of $\mathrm{BN}$, $\mathrm{BR}$, and RF for the three performance metrics. RF exhibits the highest predictive skill across the scores. $\mathrm{BN}$ and $\mathrm{BR}$ incur larger errors, which range in similar magnitudes. The very low values of MBE show that the model bias is negligible. Comparing the values of MAE and mean CRPS we find that the models incur lower error when the entire predictive distribution is evaluated instead of only the mean.

\section{Discussion and Conclusions}

The posterior predictive checks reveal that the proposed Bayesian network, Bayesian regression, and random forest are all capable of reproducing the surveyed loss data, including the critical zero and one proportions. Therefore, we conclude that the models are, in principle, suited for the application in flood loss modelling for companies.

In order to understand why RF and $\mathrm{BN}$ fit closer to the data than BR, it is necessary to recall how the models make predictions. The proposed implementations of $\mathrm{BN}$ and RF resample the actually observed losses from the training data using weights which are conditioned on the predictors. In contrast, BR assumes that probability distribution of relative loss follows a predefined functional form and generates continuous samples from this target distribution via MCMC. These samples were not necessarily contained in the training data. As a result, BN and RF fit more closely to the observations and achieve lower training error than BR. However, BN and RF seem to overfit the training data, since they also replicate the bulges in the observed distribution of relative loss (see Figure 3). The high agreement between simulated and observed relative loss for $\mathrm{BN}$ and especially $\mathrm{RF}$ might be a result of overly flexible model structures. Moreover, the training performance does often not indicate how well a model generalize in the light of new data. 
The results of this study are only the first step of a proper performance test for the candidate models. It is crucial, to further investigate the predictive capacity of Bayesian network, Bayesian regression, and random forest in a validation framework to determine the model test error (e.g. via cross-validation). Given the strong data dependence of $\mathrm{BN}$ and RF, we assume that the presented training errors distort the relative performance difference of the models for unseen data. In addition, novel approaches to flood loss estimation require for a benchmarking against established models. For example, such an experiment could investigate whether the proposed models deal better with the excess zeros and ones in the loss data than conventional stage-damage functions. Moreover, this study was limited to the investigation of company flood loss to buildings. However, other assets such as equipment, goods, and stock constitute significant shares of a companies' net worth and are likewise exposed to flooding. A comprehensive investigation of the candidate models with a focus on model validation and benchmarking including additional company assets will be provided in Schoppa et al. (2020, submitted).

The proposed multivariable probabilistic models belong to a new generation of flood loss models which embrace the complexity of flood damage processes by explicitly accounting for multiple predictors. Equally important, they inherently quantify the predictive uncertainty in their loss estimates which increases the transparency with respect to model reliability. Consequently, multivariable probabilistic models advance the representation of company vulnerability in flood risk assessment.

\section{References}

1. Breiman, L. (2001). Random Forests. Machine Learning, 45(1), 5-32.

https://doi.org/https://doi.org/10.1023/A:1010933404 324

2. Carisi, F., Schröter, K., Domeneghetti, A., Kreibich, H., \& Castellarin, A. (2018). Development and assessment of uni- and multivariable flood loss models for Emilia-Romagna (Italy). Natural Hazards and Earth System Sciences, 18(7), 2057-2079. https://doi.org/10.5194/nhess-18-2057-2018

3. Elmer, F., Thieken, A. H., Pech, I., \& Kreibich, H. (2010). Influence of flood frequency on residential building losses. Natural Hazards and Earth System Science, 10(10), 2145-2159.

https://doi.org/10.5194/nhess-10-2145-2010

4. Ferrari, S., \& Cribari-Neto, F. (2004). Beta Regression for Modelling Rates and Proportions. Journal of Applied Statistics, 31(7), 799-815. https://doi.org/10.1080/0266476042000214501

5. Gabry, J., Simpson, D., Vehtari, A., Betancourt, M., \& Gelman, A. (2019). Visualization in Bayesian workflow. Journal of the Royal Statistical Society. Series A: Statistics in Society, 182(2), 389-402. https://doi.org/10.1111/rssa.12378

6. Gelman, A., Carlin, B. J., Stern, S. H., Dunson, B.
D., Vehtari, A., \& Rubin, B. D. (2013). Bayesian Data Analysis, Third Edition (3rd Editio). Chapman and Hall/CRC. https://doi.org/10.1201/b16018

7. Gelman, A., Simpson, D., \& Betancourt, M. (2017). The prior can often only be understood in the context of the likelihood. Entropy, 19(10), 1-13. https://doi.org/10.3390/e19100555

8. Gerl, T., Kreibich, H., Franco, G., Marechal, D., \& Schröter, K. (2016). A Review of Flood Loss Models as Basis for Harmonization and Benchmarking. PLOS ONE, 11(7), e0159791.

https://doi.org/10.1371/journal.pone.0159791

9. German Federal Ministry of the Interior. (2013). Bericht zur Flutkatastrophe 2013: Katastrophenhilfe, Entschädigung, Wiederaufbau. Retrieved from https:/www.bmi.bund.de/SharedDocs/downloads/D E/veroeffentlichungen/themen/bevoelkerungsschutz/ kabinettsbericht-fluthilfe.html

10. Gneiting, T., \& Katzfuss, M. (2014). Probabilistic Forecasting. Annual Review of Statistics and Its Application, 1(1), 125-151. https://doi.org/10.1146/annurev-statistics-062713085831

11. Hasanzadeh Nafari, R., Ngo, T., \& Mendis, P. (2016a). An Assessment of the Effectiveness of Tree-Based Models for Multi-Variate Flood Damage Assessment in Australia. Water, 8(7), 282. https://doi.org/10.3390/w8070282

12. Hasanzadeh Nafari, R., Ngo, T., \& Lehman, W. (2016b). Development and evaluation of FLFAcs A new Flood Loss Function for Australian commercial structures. International Journal of Disaster Risk Reduction, 17, 13-23. https://doi.org/10.1016/j.ijdrr.2016.03.007

13. Hastie, T., Tibshirani, R., \& Friedman, J. (2009). The Elements of Statistical Learning. New York, NY: Springer New York. https://doi.org/10.1007/978-0387-84858-7

14. Hothorn, T., Hornik, K., \& Zeileis, A. (2006). Unbiased Recursive Partitioning: A Conditional Inference Framework. Journal of Computational and Graphical Statistics, 15(3), 651-674. https://doi.org/10.1198/106186006X133933

15. Huizinga, J., Meol, H. de, \& Szewczyk, W. (2017). Global flood depth-damage functions: Methodology and the Database with Guidelines. EUR 28552 EN. https://doi.org/10.2760/16510

16. International Commission for the Protection of the Rhine (ICPR). (2016). Tool and Assessment Method for Determining Flood Risk Evolution or Reduction Technical Report.

17. James, G., Witten, D., Hastie, T., \& Tibshirani, R. (2013). An Introduction to Statistical Learning. Springer Texts in Statistics (Vol. 103). New York, NY: Springer New York. https://doi.org/10.1007/978-1-4614-7138-7

18. Kreibich, H., Müller, M., Thieken, A. H., \& Merz, B. (2007). Flood precaution of companies and their 
ability to cope with the flood in August 2002 in Saxony, Germany. Water Resources Research, 43(3), 1-15. https://doi.org/10.1029/2005WR004691

19. Kreibich, H., Seifert, I., Merz, B., \& Thieken, A. H. (2010). Development of FLEMOcs - a new model for the estimation of flood losses in the commercial sector. Hydrological Sciences Journal, 55(8), 1302 1314. https://doi.org/10.1080/02626667.2010.529815

20. Liaw, A., \& Wiener, M. (2002). Classification and Regression by randomForest. $R$ News, 2(3), 18-22. Retrieved from https://www.rproject.org/doc/Rnews/Rnews_2002-3.pdf

21. Lüdtke, S., Schröter, K., Steinhausen, M., Weise, L., Figueiredo, R., \& Kreibich, H. (2019). A Consistent Approach for Probabilistic Residential Flood Loss Modeling in Europe. Water Resources Research, 2019WR026213. https://doi.org/10.1029/2019WR026213

22. McElreath, R. (2018). Statistical Rethinking. Chapman and Hall/CRC. https://doi.org/10.1201/9781315372495

23. Mechler, R., \& Weichselgartner, J. (2003). Disaster Loss Financing in Germany - The Case of the Elbe River Floods 2002. Retrieved from http://pure.iiasa.ac.at/id/eprint/7060/

24. Meinshausen, N. (2006). Quantile Regression Forests. Journal of Machine Learning Research, 7, 983-999. Retrieved from http://www.jmlr.org/papers/v7/meinshausen06a.html

25. Merz, B., Kreibich, H., Thieken, A. H., \& Schmidtke, R. (2004). Estimation uncertainty of direct monetary flood damage to buildings. Natural Hazards and Earth System Science, 4(1), 153-163. https://doi.org/10.5194/nhess-4-153-2004

26. Merz, B., Hall, J., Disse, M., \& Schumann, A. (2010a). Fluvial flood risk management in a changing world. Natural Hazards and Earth System Science, 10(3), 509-527.

https://doi.org/10.5194/nhess-10-509-2010

27. Merz, B., Kreibich, H., Schwarze, R., \& Thieken, A. H. (2010b). Review article "Assessment of economic flood damage." Natural Hazards and Earth System Science, 10(8), 1697-1724. https://doi.org/10.5194/nhess-10-1697-2010

28. Merz, B., Kreibich, H., \& Lall, U. (2013). Multivariate flood damage assessment: a tree-based datamining approach. Natural Hazards and Earth System Sciences, 13(1), 53-64. https://doi.org/10.5194/nhess-13-53-2013

29. Meyer, V., Becker, N., Markantonis, V., Schwarze, R., van den Bergh, J. C. J. M., Bouwer, L. M., et al. (2013). Review article: Assessing the costs of natural hazards - state of the art and knowledge gaps. Natural Hazards and Earth System Sciences, 13(5), 1351-1373. https://doi.org/10.5194/nhess-13-13512013

30. Middelmann-Fernandes, M. H. (2010). Flood damage estimation beyond stage-damage functions: an Australian example. Journal of Flood Risk Management, 3(1), 88-96.

https://doi.org/10.1111/j.1753-318X.2009.01058.x

31. Nagarajan, R., Scutari, M., \& Lèbre, S. (2013). Bayesian Networks in R. New York, NY: Springer New York. https://doi.org/10.1007/978-1-46146446-4

32. Olesen, L., Löwe, R., \& Arnbjerg-Nielsen, K. (2017). Flood Damage Assessment - Literature review and recommended procedure (Vol. 4). Melbourne, Australia: Cooperative Research Centre for Water Sensitive Cities. Retrieved from https://watersensitivecities.org.au/content/flooddamage-assessment-literature-review-recommendedprocedure/

33. Van Ootegem, L., Verhofstadt, E., Van Herck, K., \& Creten, T. (2015). Multivariate pluvial flood damage models. Environmental Impact Assessment Review, 54, 91-100. https://doi.org/10.1016/j.eiar.2015.05.005

34. Ospina, R., \& Ferrari, S. L. P. (2010). Inflated beta distributions. Statistical Papers, 51(1), 111-126. https://doi.org/10.1007/s00362-008-0125-4

35. Penning-Rowsell, E., Johnson, C., Tunstall, S., Tapsell, S., Morris, J., Chatterton, J., \& Green, C. (2005). The Benefits of Flood and Coastal Risk Management: A Handbook of Assessment Techniques. Middlesex University Press. Retrieved from https://repository.tudelft.nl/islandora/object/uuid:33f 2d216-c9bf-419c-b3b1-

415a6f6fd881?collection=research

36. Rözer, V., Kreibich, H., Schröter, K., Müller, M., Sairam, N., Doss-Gollin, J., et al. (2019). Probabilistic Models Significantly Reduce Uncertainty in Hurricane Harvey Pluvial Flood Loss Estimates. Earth's Future, 7(4), 384-394. https://doi.org/10.1029/2018EF001074

37. Sairam, N., Schröter, K., Rözer, V., Merz, B., \& Kreibich, H. (2019). Hierarchical Bayesian Approach for Modelling Spatio-temporal Variability in Flood Damage Processes. Water Resources Research, 2019WR025068. https://doi.org/10.1029/2019WR025068

38. Scawthorn, C., Flores, P., Blais, N., Seligson, H., Tate, E., Chang, S., et al. (2006). HAZUS-MH Flood Loss Estimation Methodology. II. Damage and Loss Assessment. Natural Hazards Review, 7(2), 72-81. https://doi.org/10.1061/(ASCE)15276988(2006)7:2(72)

39. Schoppa, L., Sieg, T., Vogel, K., Zöller, G., \& Kreibich, H. (2020). Probabilistic Flood Loss Models for Companies. Water Resources Research. Submitted.

40. Schröter, K., Kreibich, H., Vogel, K., Riggelsen, C., Scherbaum, F., \& Merz, B. (2014). How useful are complex flood damage models? Water Resources Research, 50(4), 3378-3395. 
https://doi.org/10.1002/2013WR014396

41. Scutari, M. (2010). Learning Bayesian Networks with the bnlearn R Package. Journal of Statistical Software, 35(3). https://doi.org/10.18637/jss.v035.i03

42. Scutari, M., \& Denis, J.-B. (2014). Bayesian Networks With Examples in R. Texts in Statistical Science Series. Boca Raton: Chapman and Hall/CRC. https://doi.org/10.1201/b17065

43. Seifert, I., Kreibich, H., Merz, B., \& Thieken, A. H. (2010). Application and validation of FLEMOcs - a flood-loss estimation model for the commercial sector. Hydrological Sciences Journal, 55(8), 13151324. https://doi.org/10.1080/02626667.2010.536440

44. Sieg, T., Vogel, K., Merz, B., \& Kreibich, H. (2017). Tree-based flood damage modeling of companies: Damage processes and model performance. Water Resources Research, 53(7), 6050-6068. https://doi.org/10.1002/2017WR020784

45. Sieg, T., Vogel, K., Merz, B., \& Kreibich, H. (2019). Seamless Estimation of Hydrometeorological Risk Across Spatial Scales. Earth's Future, 7(5), 2018 EF001122. https://doi.org/10.1029/2018EF001122

46. Simpson, D., Rue, H., Riebler, A., Martins, T. G., \& Sørbye, S. H. (2017). Penalising model component complexity: A principled, practical approach to constructing priors. Statistical Science, 32(1), 1-28. https://doi.org/10.1214/16-STS576

47. Sultana, Z., Sieg, T., Kellermann, P., Müller, M., \& Kreibich, H. (2018). Assessment of Business Interruption of Flood-Affected Companies Using Random Forests. Water, 10(8), 1049. https://doi.org/10.3390/w10081049

48. Thieken, A. H., Müller, M., Kreibich, H., \& Merz, B. (2005). Flood damage and influencing factors: New insights from the August 2002 flood in Germany. Water Resources Research, 41(12), 1-16. https://doi.org/10.1029/2005WR004177

49. Thieken, A. H., Bessel, T., Kienzler, S., Kreibich, H., Müller, M., Pisi, S., \& Schröter, K. (2016). The flood of June 2013 in Germany: how much do we know about its impacts? Natural Hazards and Earth System Sciences, 16(6), 1519-1540. https://doi.org/10.5194/nhess-16-1519-2016

50. Vogel, K., Riggelsen, C., Merz, B., Kreibich, H., \& Scherbaum, F. (2012). Flood damage and influencing factors: A Bayesian network perspective. Proceedings of the 6th European Workshop on Probabilistic Graphical Models, PGM 2012, 347354.

51. Vogel, K., Riggelsen, C., Scherbaum, F., Schröter, K., Kreibich, H., \& Merz, B. (2014). Challenges for Bayesian network learning in a flood damage assessment application. In Safety, Reliability, Risk and Life-Cycle Performance of Structures and Infrastructures (pp. 3123-3130). CRC Press. https://doi.org/10.1201/b16387-452
52. Vogel, K., Weise, L., Schröter, K., \& Thieken, A. H. (2018). Identifying Driving Factors in FloodDamaging Processes Using Graphical Models. Water Resources Research, 54(11), 8864-8889. https://doi.org/10.1029/2018WR022858

53. Wagenaar, D., Lüdtke, S., Schröter, K., Bouwer, L. M., \& Kreibich, H. (2018). Regional and Temporal Transferability of Multivariable Flood Damage Models. Water Resources Research, 54(5), 36883703. https://doi.org/10.1029/2017WR022233

54. Yeo, I.-K. (2000). A new family of power transformations to improve normality or symmetry. Biometrika, 87(4), 954-959. https://doi.org/10.1093/biomet/87.4.954

55. Zhai, G., Fukuzono, T., \& Ikeda, S. (2005). MODELING FLOOD DAMAGE: CASE OF TOKAI FLOOD 2000. Journal of the American Water Resources Association, 41(1), 77-92. https://doi.org/10.1111/j.1752-1688.2005.tb03719.x 